\title{
CARRINHO TRIMÓVEL: MAIS CONFORTO E SUSTENTABILIDADE NO TRANSPORTE DE COMPRAS
}

\author{
KARINE FLOSS | UNOESC \\ DANIEL PINHEIRO, Esp. | UNOESC \\ EDUARDO CIPRIANI SCHWENGBER, M.SC. | UNOESC \\ LIDIANE CAMILOTI, M.SC. | UNOESC
}

O presente trabalho de conclusão de curso envolveu o redesign do produto do carrinho de compras, visando melhorar sua ergonomia e funcionalidade e buscando aplicar no produto aspectos que solucionem alguns problemas encontrados no estudo de campo. A metodologia aplicada para o desenvolvimento deste produto é a metodologia projetual de Löbach (2001) está dividida em quatro etapas que conduziram ao resultado final. Também realizaram-se estudos sobre o produto e as necessidades do consumidor para o transporte de compras, como compras em supermercados, feiras e demais comércios. A partir de pesquisas e sugestões dos consumidores foram desenvolvidas algumas propostas para possíveis aplicações no novo modelo de carrinho de compras. Com as gerações de alternativas, essas ideias foram sendo melhoradas e assim definida em banca a melhor solução a qual foi desenvolvida. A alternativa traz como objetivo o conforto do consumidor no transporte de suas compras, evitando problemas ergonômicos, além de ser um produto sustentável, funcional, ser atraente para os consumidores.

O estudo teve como objetivos a realização de estudo de campo sobre o processo de transporte das compras nos supermercados e feiras; A pesquisa de materiais e processos de produção que possam ser aplicados no produto, de modo sustentável; A aplicação da ergonomia ao novo modelo, e; O desenvolvimento de um novo carrinho de compras que possua multifuncionalidade como um de seus benefícios, ampliando assim a vida útil e reduzindo a produção de outros produtos similares.

Observou-se, na primeira fase do projeto, a literatura específica da área do design, bem como a pesquisa com usuários. Durante as fases posteriores de projeto, uma das maiores preocupações foi com a definição de materiais. Foram utilizadas como algumas das indicações para escolha dos materiais e dos processos de baixo impacto, a partir do que consta em (MANZINI E VEZZOLI, 2008):
- Evitar inserir materiais tóxicos e danosos no produto;

- Minimizar o risco de materiais tóxicos e danosos;

- Evitar acabamentos tóxicos e danosos;

- Usar materiais renováveis;

- Evitar usar materiais que estão por se exaurir;

- Usar materiais renováveis;

- Usar materiais reciclados, em separado ou junto com outros materiais virgens;

- Escolher tecnologias de transformação ou materiais de baixo impacto.

Definiu-se por utilizar termoplástico reciclado na composição de componentes; Aço carbono ou alumínio, conforme disponibilidade, na produção da estrutura; Tecido lona, preferencialmente de reuso, na produção das cestas (como substituto, pode ser utilizado o tecido de algodão, preferencialmente certificado); materiais de isolamento térmico na produção da cesta térmica; e painel fotovoltaico para produção de energia a ser utilizada pelo celular do usuário, bem como, numa melhoria futura do projeto, resfriamento do compartimento térmico.

Como aspectos ergonômicos, foi realizado um estudo a campo, observando compradores e os materiais usados no transporte das compras, seja até o seu veículo ou até residência (compras a pé). Constataram-se vários problemas ergonômicos como carga com peso excessivo, postura incorreta no transporte, choque térmico no contato do usuário com mercadorias resfriadas, uso incorreto das sacolas de compra do modelo retornável.

Como projeto mecânico do carrinho, optou-se por mecanismos que possam reduzir o tamanho do mesmo, em situações de não uso, bem como expansões organizadas de acordo com a necessidade momentânea do usuário (Figura 01). 


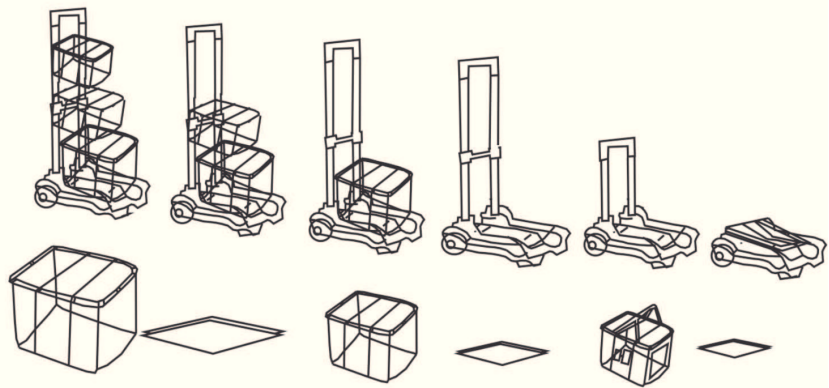

Figura 01: Projeto mecânico. Fonte: 0 s autores

Na sequência das etapas projetuais e de pesquisa, foram elaboradas visualizações tridimensionais para a melhor compreensão dos aspectos de uso e estéticos do produto, conforme figura 02.

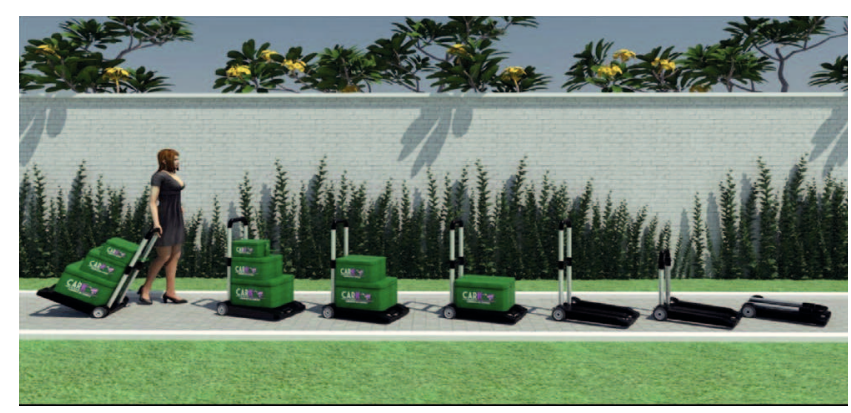

Figura 02: Esquema de uso.

Fonte: 0 s autores

Para a conclusão do projeto, gerou-se a prototipagem física com materiais o mais próximos possíveis das escoIhas realizadas e após a prototipagem, o produto foi inserido em situação de uso real, para avaliação ergonômica.

Considera-se que os objetivos foram atingidos dentro do esperado e constatou-se que novos estudos e melhorias são possíveis, bem como, na futura produção seriada, há a possibilidade de melhoria contínua do produto e materiais.

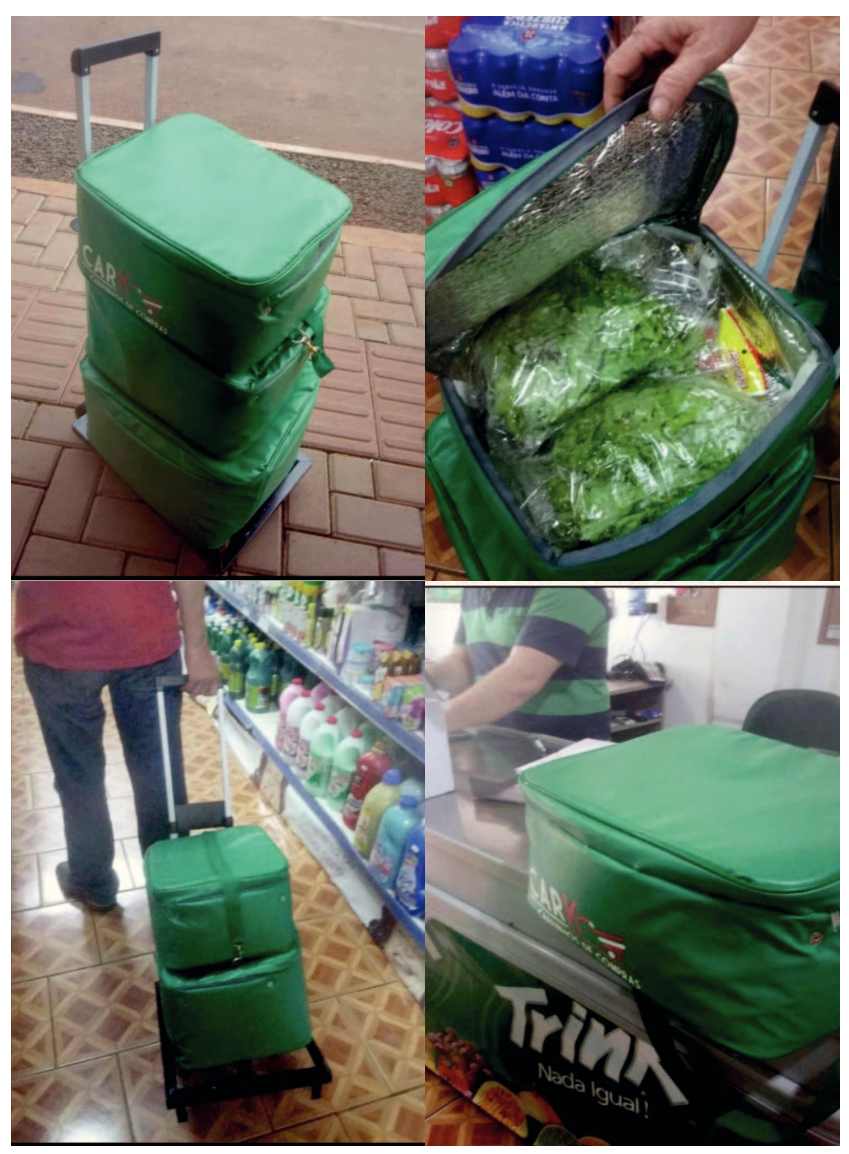

Figura 03: prototipagem e testes.

Fonte: 0 s autores

\section{REFERÊNCIAS}

CARDOSO, Rafael. Uma introdução à história do design. São Paulo, Blücher, 2002.

LIMA, Marco Antonio Magalhães, Introdução aos materiais e processos para designers. Rio de Janeiro, Ciência moderna Ltda. 2006.

LESKO, Jim, Design industrial: Guia de materiais e fabricação. São Paulo, Blucher 2012.

LÖBACH, Bernd. Design industrial: Bases para a configuração dos produtos industriais. São Paulo: Blucher, 2001.

MANZINI, E.; VEZZOLI, C.. O desenvolvimento de produtos sustentável. Tradução de Astrid de Carvalho;-1. ed.2 reimpr-São Paulo. Editora da universidade de São Paulo, 2008. 